\title{
Conceptual Fundamentals of the Labor Market Development in Ukraine in Terms of the COVID-19 Pandemic
}

\author{
Dmitriy Babych *[0000-0002-0709-8333], Svitlana Babych [0000-0002-1081-7685], \\ Iryna Ternova [0000-0002-8173-2689] \\ V.N. Karazin Kharkiv National University, Kharkiv, Ukraine \\ *Dvb123321@gmail.com
}

\begin{abstract}
The article deals with the current trends in the labor market in Ukraine caused by the COVID-19 pandemic. There has been a decline in demand for non-essential goods and products and limited mobility of human resources, which has slowed the pace of the manufacturing sector development. The structural changes of the modern labor market in 2020 2021 have been analyzed and the most demanded professions, preferences of job seekers and employers are determined. It is established that today, in the labor market there is a decrease in demand and supply of labor, which became the basis for an increase in the unemployment rate, which provoked labor mimicry, which was to be the basis for the emergence of new types professionally adapted to conditions caused by quarantine restrictions. It is determined that a new model of the labor market is being formed, and the demand for retraining of employees will grow. The concept of the state regulation of the labor market is developed and the scientific and methodological principles of its formation are substantiated on the basis of certain social and economic methods, including the methods of modern educational technologies which represent the most rational and efficient means of achieving the set goal - improving the level of human capital development in terms of the global crisis caused by the COVID-19 pandemic.
\end{abstract}

Keywords: labor market, unemployment, wages, COVID-19, mobility of human resources, adaptation period, top professions.

\section{INTRODUCTION}

The COVID-19 pandemic and the implemented national quarantines have created a quite tense situation in the labor market and caused a shocking situation in the economy, and this, foremost, affected the small and medium business sector. Employers have faced an unexpected issue: how to maintain the staff and the business at the same time. This has significantly impacted the formation of the modern labor market, exacerbated existing problems in the field of employment, as well as caused new ones. Wages are an important component of social and labor relations, an opportunity to satisfy multidirectional economic interests, which are quite difficult to unite. For a long time now, the issue of compensation for work has been one of the key issues for Ukraine, as it resonates: there is a significant difference between high cost of living and low labor costs, especially during a pandemic period characterized by a number of restrictions that not only slow down work for some sectors of the economy, but also provoke the search for new ways and mastering of new professions and skills for additional income.

\section{RESEARCH ANALYSIS}

The work of such scientists as: N. Azmuk [1], A. Dvigun [2], S. Kulitsky [3], L. Lavrynenko [4], E. Libanova [5], O. Poznyak [5], V. Yablonsky [6], L. Shamileva [7], O. Khandiy [7] and others is devoted to the study of the national labor market in Ukraine in the context of the COVID-19 pandemic and its existing problems. Therewith, aspects related to the study and evaluation of the modern labor market development require consideration of the consequences of the COVID19 pandemic and more detailed research.

\section{AIMS}

Generalization of the main trends in the labor market, analysis of the most demanded and highly paid professions in terms of the COVID-19 pandemic and 
substantiation of the conceptual foundations of the modern labor market in Ukraine.

\section{RESULTS}

One of the most complex elements of the market economy is the labor market, which reflects almost all socioeconomic processes occurring in the country. The most troubling issue is the relationship between the interests of an employee and their employer in terms of operation and determining the price of labor. The labor market in Ukraine has experienced an even greater economic crisis, related to COVID-19, than in Europe. This is largely due to the shadowing of our economy. ILO projections highlight the danger of a COVID-19 labour market legacy of increased geographic and demographic inequality, rising poverty and fewer decent jobs [8]. There have been phenomena unseen over the past few decades, such as the closed borders, restrictions on some economic activities, forced returns of well successful migrants, and the impossibility of another round trip by circular migrants [5].

In order to make substantiated management decisions, it is necessary to have high-quality statistics obtained by constant monitoring of the real state of the social and labor area and clarify the factors that cause certain trends and transformations in social and labor relations [1]. Today, in a pandemic, significant changes have happened in the labor market, which took place in two stages. The first stage was characterized by a significant decline, supported by the implementation of strict quarantine measures within the country, which most negatively affected the development of economic activities that involve or allow large crowds of people in one place, or their lasting communication, and work activities at a dangerous distance, taking into account potential infection. At the same time, a significant factor contributing to the slowdown of some economic activities was the decline in demand for non-essential goods and products and the restriction of human mobility, which in its turn contributed to the rapid downfall of the manufacturing sector.

The second stage was the adaptation period in terms of the corona crisis. The practice, which implemented measures aimed at mitigation of the negative effects of the pandemic by supporting the population and businesses, has become popular. Social assistance and transfers from the state made a significant contribution to income growth. Thus, to support the population, a onetime assistance of up to $8,000 \mathrm{UAH}$ was organized, which was received by employees (including entrepreneurs) who lost part of their income due to lockdown. Another example of the state support was the adoption of a number of temporary tax benefits and the write-off of small debts for sole proprietors (entrepreneurs).
However, despite these stabilization measures, the unemployment rate is growing. In January-March 2021, 1.5 million citizens looking for a job used the services of the Public Employment Service. Out of these, 680 thousand people had the status of registered unemployed, which is $34 \%$ more than in the corresponding period of the last year (Figure 1) [9].

Thus, based on the given chart, the unemployment rate continues to grow, although after the diminishing of quarantine measures, demand and supply of labor increased.

\section{Number of the unemployed, in thousands of people}

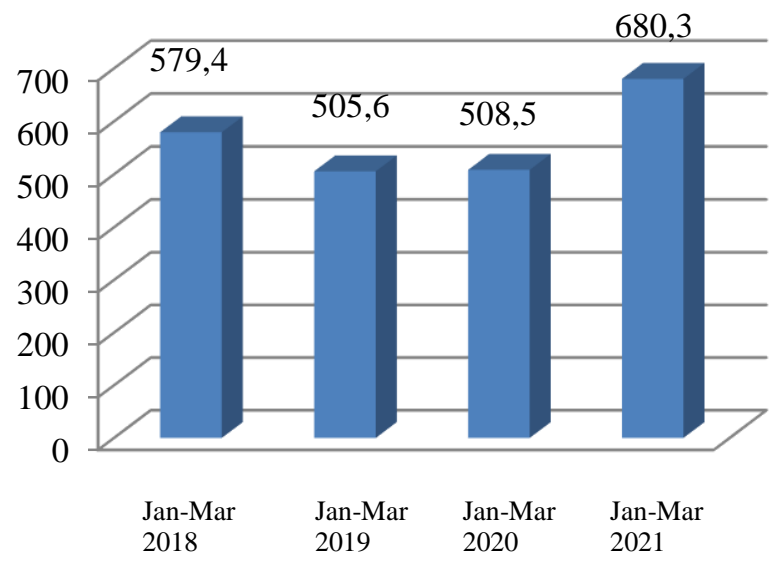

Figure 1 Number of the unemployed, in thousands of people [10]

At the same time, the number of job offers decreased by almost $25 \%$ compared to last year. As of April 1, 2021, on average in Ukraine, six unemployed people apply for one workplace. This is due to the economic losses from restrictions and increase in indeterminacy for businesses and employees.

The number of people wishing to find a job has also decreased, as the seasonal factor and high sickness rate have caused the decrease in activity. The share of economically inactive men increased from $11 \%$ to $24 \%$ during quarantine. The number of economically inactive women has also increased, but not so rapidly. This is entirely due to the fact that most women continued to work, as their work activities were related to the areas that continued to function during restrictions, while men were employed mostly in the sectors affected most heavily by the pandemic.

Thus, the negative financial results for 2020 showed a number of economic activities, including transport, services, temporary accommodation and catering, real estate transactions, professional, scientific and technical activities, arts, sports, entertainment and recreation, education.

Transport has suffered the most among all other types of economic activities from the impact of quarantine. According to the results of last year, there was a rapid 
decline in the area of passenger transportation services, which was never witnessed for all years of statistical observations. The economic activities related to the provision of individual, tourist services, catering and temporary accommodation were also in a difficult situation. The number of catering establishments operating continues to decline, but at the same time, open catering establishments are getting better at adapting to takeaways and delivery, which has helped increase the income of their owners. Arts, sports, entertainment and recreation services are also in a bad condition, and have been actually suspended due to the de facto ban on lockdown activities and the maintenance of significant restrictions during the quarantine mitigation period. Due to the closure of borders, drop in prices in world markets, the ban on exports and imports, the industry also got under a significant influence.

Accordingly, it should be noted that in 2020 the Ukrainian economy suffered significant losses due to the impact of the COVID-19 pandemic: the actual decrease in employment rate in Ukraine; growth in the number of the unemployed in Ukraine; reduction of the number of Ukrainians working abroad (labor migrants); reduction of the income of the Ukrainian population from selling their own labor and self-employment due to the reduction of wages, losses of jobs and the income of entrepreneurs [3]. There are also losses in community budgets due to the lower tax revenues and reduced entrepreneurship due to the quarantine losses [2]. However, it is the rapid adaptation of certain economic activities to the conditions of the pandemic that became the key to the gradual upturn of production processes, which in the future will allow responding quickly to changes in both external and internal environment.

During the pandemic, many employers in different sectors of the economy were able to create different conditions for the adaptation of their business during the inconstant conditions of the corona crisis. The number of employed people, who may be let go of as a result of the economic recession is proposed to estimate on the basis of expert assessments of changes in production, while maintaining productivity achieved over the past 2-3 years [7].

In the labor market in Ukraine, the IT area has the biggest popularity, which is quite highly paid, as the share of the advertising market is rapidly absorbed by the Internet resources and is about $25 \%$ of a total turnover. It is difficult to find a type of economic activity that would do without information technology specialists. The processes of digitalization of the economy increase the flexibility of employment, which is accompanied by a decrease in social protection of workers, while there is an increase in the qualification and professional versus digital gap between them [1]. As for vacancies, the largest number of them are offered in the trade field. The main tendency of recent years will be the growth of professions, which are still rarely taught in Ukraine, since on all job search sites, vacancies are mostly related to the sale of goods, i.e. sales manager. No special education is required for this occupation, as the main factor that will help succeed is sociability. The development of modern companies and the reorganization in the field of management have made an HR manager (human resources manager) one of the most popular professions. It can be stated that this is a certain trend in today's labor market.

In the upcoming years, such a profession as a logistician will also be relevant, as $15 \%$ of world GDP is spent on logistics. While Ukraine is geographically at the crossroads of trade routes, it needs more and more managers to run traffic flows. A modern logistician is a manager, marketer and economist. Engineering and architecture specialties, which seemed to be gone, are getting increasingly popular. With the growth of urbanization both in the world and in Ukraine, new buildings are to replace the old ones, megacities are expanding, both residential neighborhoods and country cottage towns are emerging. Among the job portals you can also often find a search for SMM-specialists: Social Media Coordinator, Social Media Content Creator. Such a number of options once again proves the fact that this profession is fast-growing and very promising in terms of job search, as the right interaction with users through social networks is the key to successful business growth: forming and improving the brand image, increasing sales.

As for the service sector, the development of the culture of coffee consumption has made a barista, the specialist in the preparation and serving of coffee, one of the most popular professions in the field of catering. The beauty industry needs stylists, makeup and nail artists. Anyone can learn this, six-month courses compensate the money spent on training in a year.

During the quarantine, not only the number of vacancies decreased. The number of resumes on job search sites has also decreased, although the number of the unemployed in Ukraine has increased significantly [6].

Summarizing all the above, we have identified the top in-demand professions among the most popular job portals: work.ua [11] (Figure 2) and robota.ua (Figure 3).

As it can be seen from the chart, the first place in the ranking is occupied by IT, the next vacancies by popularity are sales manager and personnel manager, i.e. those professions that will always be relevant, because information technology, qualified professionals who can quickly and most efficiently sell products, the search and selection of personnel and maintaining a positive climate within the team are some of the most important factors in successful development of any business.

Regarding robota.ua. [9], its top professions are slightly different, since there is an SMM-specialist, 
content manager, l ogistics manager, teacher and various working specialties. This can be explained by the fact that different portals [12] of job placement have their own target audience, some place their vacancies only by one principle, while the other use various different tools.

\section{Top 15 professions in the labor market on the portal work.ua.}

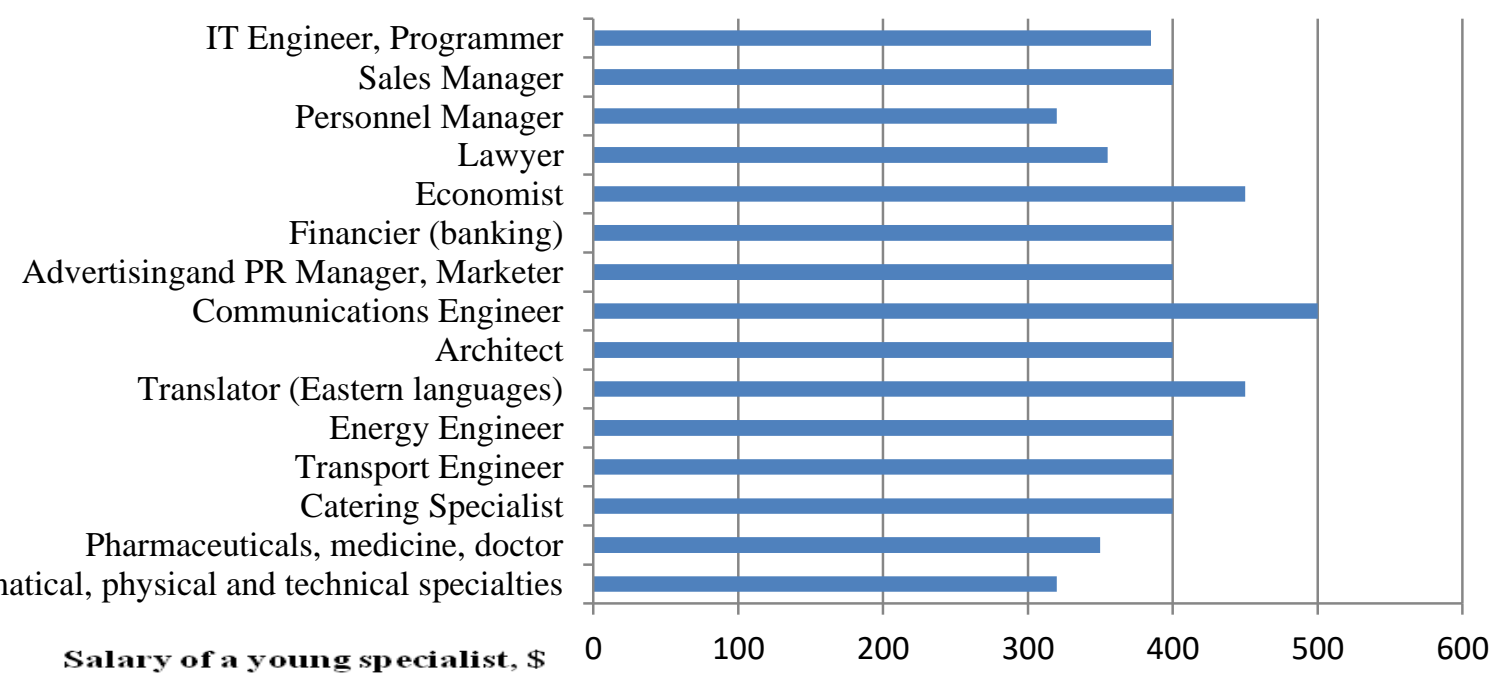

Figure 2 Rating of the most in-demand professions according to the statistics of the job placement portal work.ua.

Top 10 professions in the labor market on the portal robota.ua.

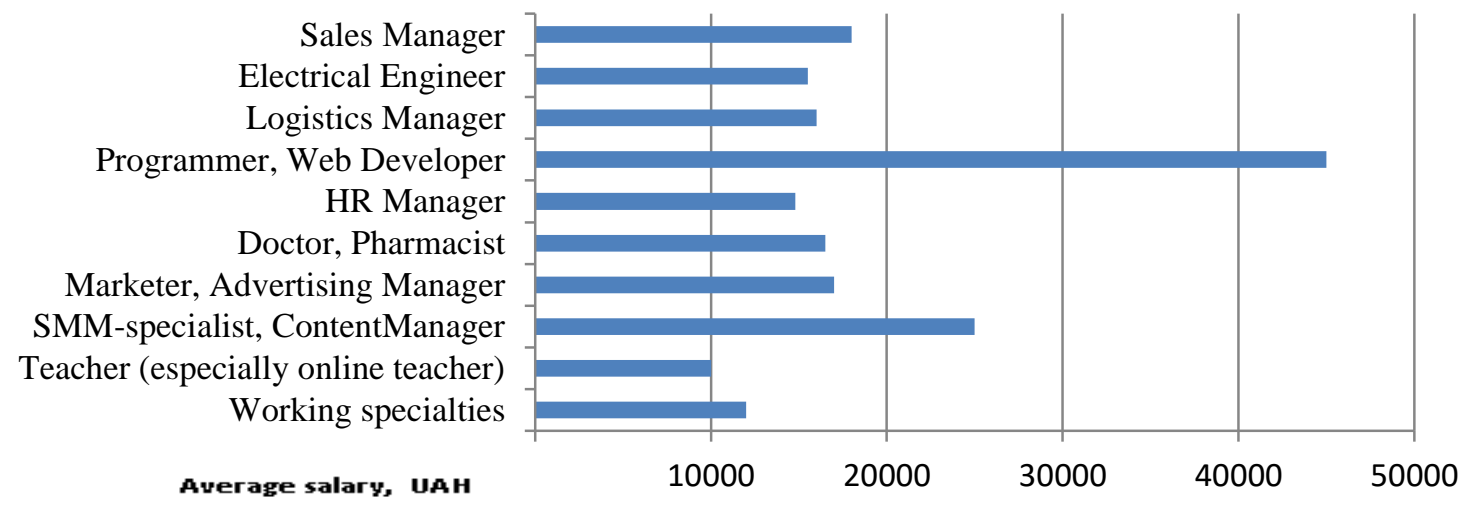

Figure 3 Top 10 in-demand professions according to the statistics of the job placement portal robota.ua.

After analyzing the top in-demand professions, we can determine the highest-paid professions in the labor market in Ukraine. From the two graphs above, we can conclude that the average salary price of a vacancy differs depending on the portal of its placement. Therefore, the concept of forming a labor market development policy should take into account globalization and integration processes, the development of digital networks and IT, programming and automation of production processes, and the growth of customer orientation of retail chains. For some businesses and employees, events with quarantine will be an impetus for positive changes and the introduction of new technologies $[4,13]$.

Thus, with the concept of forming a labor market development policy (Figure 4) based on the definition of the main subjects of the management system, elements that determine the strategy for the development of human capital, the functions of state regulation and the main directions of building an educational strategy [14], we determined that the main stages of building a strategy are: the development of a regulatory framework within their competence [15]; the formation of goals, objectives and principles of the system for the development of professional competencies from IT, arising from the concept of economic development; analysis [16] and consideration of external factors; programming, including the development of a system of procedures, measures and personnel technologies; monitoring of "human resources" (implementation of specific measures and assessment of their effectiveness); control at all hierarchical management levels. 


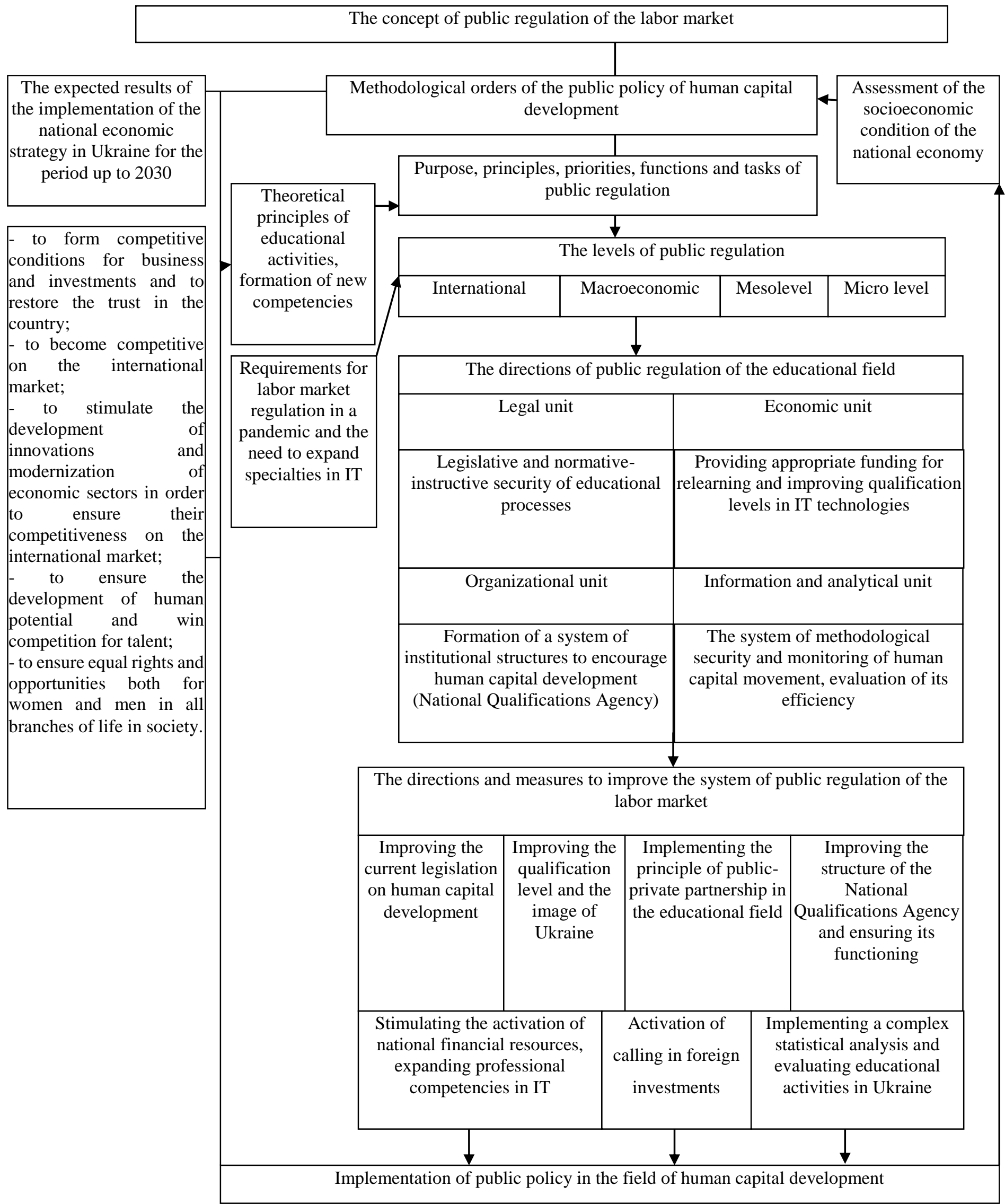

Figure 4 The concept of public regulation of the labor market 
The main subjects of the management system [17] are: public administration bodies, regional management bodies, personnel of divisions of the "Human Resources" Management System, Information and management relations and flows, the main methods of labor market management. The functions of managing the human capital development policy include: labor market analysis; forecasting educational policy; planning the number of specialists to achieve a balance of supply and demand; information support.

The existing educational system in Ukraine fully meets the need for training, retraining and improving qualification levels of personnel and, moreover, has the opportunity to train specialists from the employment center, from enterprises of various types of economic activity and various forms of ownership.

The prospects of the human capital development system are as follows: the further development of the system of postgraduate education institutions in Ukraine; the introduction of progressive information methods of teaching, including distance learning; improving the material and technical base and living conditions; expanding relations with enterprises to provide educational, advisory, informational and other services; expanding and strengthening the foreign economic activity [18] of educational institutions in the direction of exchanging experience on advanced progressive technologies, know-how, etc.

The use of the concept of the labor market development policy involves the management of the system of retraining and improving qualification levels of managers and specialists, gives companies the ability [19] to optimize the cost of staff training and increase the efficiency of management.

Based on the generalization of the leading foreign experience, it is advisable to create a system of continuing education, which contains the following areas: professional training in universities and in specialized educational institutions in the field of IT; retraining of certified specialists; regular education in the system of advanced training, as well as directly on special courses.

Thus, in accordance with the concept of labor market development policy management of the system of retraining and improving qualification levels of managers and professionals will provide the necessary level of human capital skills, meet the interests of citizens in continuous professional development in accordance with labor market conditions, meet the needs of society and the country from highly qualified, competitive specialists.

\section{CONCLUSION}

As a result of the pandemic, the economy of Ukraine went through two stages: the period of rapid decline and the adaptation period, which caused some changes in the labor market. Changing environmental conditions have forced business owners to reorient their activities and adapt to running their businesses under the restrictions caused by COVID-19. However, despite all of this, a number of economy sectors have fallen significantly, as the demand for both goods and labor has declined due to the high sickness rate and seasonal factor. Thus, the activities of the production area slowed down, while the activities in the field of art, sports, entertainment and recreation were actually stopped. There is also a critical decline in passenger traffic, drop in prices on world markets, a ban on exports and imports, which has left its mark, both in services and the industry as a whole. The search for additional ways of income has forced both employees and those wishing to find a job to reorient towards new types of activities, while employers got pushed to creating safer working conditions, the opportunity to work and promote their services and products in new ways. This decision was the promotion of one's product through social networks, interaction with people online, which became the foundation for the emergence of new professions. Adaptation of the labor market in terms of the COVID-19 pandemic continues, whereas the demand for retraining of workers will grow. Thus, the labor market of Ukraine is not standing still, while changes in both internal and external factors are becoming a catalyst for the further development of new areas of activity that can quickly adapt to inconstant conditions.

In order to implement the concept of labor market development policy, certain socioeconomic methods are proposed, including methods of modern educational technologies, which, in our opinion, are the most rational and efficient means of achieving the set goal - increasing the level of human capital development in times of the global crisis caused by COVID-19. The development of human capital is under the influence of informatization, the formation of intellectual labor, which are the foundation of innovative development. The process of the intellectual economy formation under the influence of human capital is executed at both macro and micro levels and has the potential for self-development through a feedback mechanism. Thus, the development of human capital should be carried out through two simultaneous processes: on one hand - the development of artificial intelligence, which allows meeting the information needs of almost any user, on the other hand - the development of human intelligence.

\section{REFERENCES}

[1] Azmuk, N.A. (2020), Modern Labor Market Challenges during the Transition to Digital Economy. Modern Economics, vol. 19 (1), pp. 613, DOI: 10.31521/modecon.V19(2020)-01 
[2] Dvihun, A.O. (2020), Crisis: New Community Opportunities and Challenges for Decentralization. The 10th International scientific and practical conference "Scientific achievements of modern society", Cognum Publishing House, Liverpool, United Kingdom. May 27-29, pp. 408-413.

[3] Kulytskyi, S. (2020), Ukrainian labor market under the influence of the COVID-19 pandemic: the state and assessment of development prospects. Ukraine: events, facts, comments, vol. 12, pp. 43-57, available at: http://nbuviap.gov.ua/images/ukraine/2020/ukr12. pdf

[4] Lavrynenko, L.M. The quarantine labor market and the professions that will be in demand after the COVID-19 pandemic. International scientific ejournal $\quad \mathrm{O} \mathrm{O} О \Sigma, \quad$ available at: https://www.ukrlogos.in.ua/10.11232-26634139.09.13.html

[5] Libanova, E.M. and Pozniak, O.V. (2020), External labor migration from Ukraine: the impact of COVID-19, Demographl and Social Economy, vol. 4 (42), pp. 25-40. DOI: 10.15407/dse 2020.04 .025

[6] Yablonskyi, V. and Tymchenko, O. The labor market in quarantine: what threatens the continuation of restrictions, VoxUkraine, available at: https://voxukraine.org/rinok-pratsi-na-vihodi-zkarantinu/

[7] Shamileva, L.L. and Khandij, O.O. (2020), Assessment of the impact of the financial and economic crisis and the COVID-19 pandemic on the national labor market, Economic Herald of the Donbas, vol. 3, no. 61, pp. 177-182. DOI: 10.12958/1817-3772-2020-3(61)-177-182

[8] World Employment and Social Outlook-Trends 2021. (2021), ILO, available at: https://www.ilo.org/global/research/globalreports/weso/trends2021/lang--en/index.htm

[9] Transparent work: interesting insights of the labor market from robota.ua (2020), available at: https://rabota.ua/prozora?keyword=\&cityId=0\&ru bricId

[10] State Statistics Service of Ukraine (2021), available at: http://www.ukrstat.gov.ua/
[11] Job search site in Ukraine, available at: https://www.work.ua/?setlp=ua

[12] Subhash Chander and Ashwani Kush (2013), "Vulnerabilities in Academic E-governance Portals", IJCNIS, vol. 5, no. 3, pp. 56-62, DOI: 10.5815/ijcnis.2013.03.07

[13] Xiao Xiong. Xu, Wan ting. Ye and Qiong. Shang (2011), "Using New Technologies to Support Collaborative Learning for College Students", IJEME, vol. 1, no. 3, pp.73-78, DOI: 10.5815/ijeme.2011.03.11

[14] Mohamed A. Alket (2017), "A Network-Based Peer Evaluation Strategy", International Journal of Modern Education and Computer Science, vol. 9, no. 4, pp. 32-42, DOI: 10.5815/ijmecs.2017.04.04

[15] Korystin, Oleksandr and Svyrydiuk, Nataliia (2021), "Formation of security competences in law enforcement activities", Nauka i Pravookhorona, vol. 1 (51), pp. 191-198, DOI 10.36486/np.2021.1(51).20

[16] Tkachenko, Volodymyr Kwilinski, Aleksy Korystin, Oleksandr Svyrydiuk, Natalia and Tkachenko, Iryna (2019), “Assessment of information technologies influence on financial security of economy", Journal of security and sustainability issues, march, vol. 8, no. 3, pp. 375385, DOI: 10.9770/jssi.2019.8.3(7)

[17] Kamyab Khajehei (2018), "Preserving Privacy in Cloud Identity Management Systems Using DCM (Dual Certificate Management)", International Journal of Wireless and Microwave Technologies, vol. 8, no. 4, pp. 54-65, DOI: 10.5815/ijwmt.2018.04.04

[18] Kotlyarevsky, Ya.V. Melnychenko, A.A. Ivanytska, O.M. Semenyuk, E.P. Kniaziev, S.I. and Melnikov, O.V. (2020), "New Economy: Evolution of Forms and Research Methodology", Sci. Innov., vol. 16, no. 1, pp. 15-30, DOI: 10.15407/scine16.01.015.

[19] Korystin, Oleksandr and Svyrydiuk, Nataliia (2021), "Activities of Illegal Weapons Criminal Component of Hybrid Threats", Proceedings of the International Conference on Economics, Law and Education Research (ELER 2021), vol. 170, 22 March, pp. 86-91, DOI: 10.2991/aebmr.k.210320.016 